\title{
FEMINISMOS, SABERES E PRÁTICAS DECOLONIAIS
}

HOLLANDA, Heloisa Buarque de. (org.). Pensamento feminista hoje: perspectivas decoloniais. Rio de Janeiro: Bazar do Tempo, 2020.

O livro Pensamento feminista hoje: perspectivas decoloniais é o terceiro da série organizada pela renomada pesquisadora brasileira Heloísa Buarque de Hollanda e publicada pela editora Bazar do Tempo no início de 2020. Apesar da perspectiva do feminismo decolonial e de autoras decoloniais já aparecerem, ainda que timidamente, nas edições anteriores (Pensamento feminista: conceitos fundamentais e Pensamento feminista brasileiro: formação e contexto, ambos publicados em 2019), é nesta terceira edição que os diversos pensamentos feministas que se baseiam em epistemologias e práticas decoloniais são amplamente discutidos. A obra abraça textos de importantes intelectuais feministas da América Latina, do Caribe e de África, apresentando um olhar analítico de como o giro decolonial é importante para pensar não só gênero como também outras categorias, a exemplo de raça, classe e religião, por meio de um viés de percepção da diversidade de mulheres do chamado Cone Sul.

Nesta edição, podemos contemplar, nas duas primeiras partes, 16 textos importantes para o fazer feminista decolonial. Ainda que alguns já estivessem disponíveis em outros espaços de divulgação do saber, a exemplo da internet, um dos grandes feitos dessa obra é a de disponibilizá-los de forma traduzida para a Língua Portuguesa, o que pode estimular novas pesquisas nessa área em território nacional. Além dos artigos e ensaios, o livro ainda conta com obras de artistas plásticas brasileiras contemporâneas que também se encontram no propósito do fazer decolonial, mostrando que as práticas e pedagogias decoloniais devem fazer parte do cotidiano de toda aquela que se mostra disposta a decolonizar poder, saber, ser e gênero.

Durante toda a obra, os textos estão organizados de modo que, ao mesmo tempo em que se complementam, também adicionam novos tópicos, construindo uma unidade coesa quando pensamos nas categorias de gênero, raça, classe, orientação sexual, religião, localização geográfica/geopolítica e, não menos importante, elaboração epistemológica: quais sujeitos e sujeitas são observados, quais elaboram saberes, quais pessoas são apagadas, reduzidas ou generalizadas, como produzir novos saberes a partir dos novos locais e dos produtores de conhecimento.

Na primeira parte do livro, intitulada "Desafiando Matrizes", as ideias iniciais de uma decolonialidade e de um feminismo decolonial e afro-latino-americano

\section{Francielle Suenia da Silva}

Doutoranda do Programa de Pós-Graduação em Letras, da Universidade Federal da Paraíba, sob orientação da Profa. Dra. Luciana Eleonora de Freitas Calado Deplagne. Bolsista Capes. Mestra em Linguagem e Ensino (UFCG). Graduada em Letras - Língua Portuguesa (UEPB). E-mail: franciellesu@ gmail.com 
podem ser vistas no texto "Por um feminismo afro-latino-americano", da brasileira Lélia Gonzalez, que faz uma interessante abordagem de gênero e raça acerca da mulher afro-latino-americana e os problemas que enfrentam tanto enquanto mulheres racializadas e não ouvidas no feminismo hegemônico, - sofrendo, portanto, apagamento racial -, quanto nos movimentos étnicos que incorporaram práticas sexistas. Por sua vez, María Lugones, no ensaio "Colonialidade e gênero", observa como a colonialidade de gênero atua de forma prejudicial às "mulheres de cor" de todo o continente americano. No texto, Lugones evidencia os problemas da generificação e do binarismo - inexistentes nas sociedades pré-coloniais, segundo a autora. De forma objetiva, a argentina aponta que mulheres brancas mestiças pobres também sofrem as consequências do que vai chamar de feminismo branco burguês. Vale, ainda, mencionar as críticas de Lugones ao posicionamento de Anibal Quijano quanto ao gênero, ampliando a perspectiva dessa categoria em uma abordagem decolonial.

Uma das poucas vozes de África na coletânea - fato que podemos considerar lamentável, tendo em vista a quantidade de intelectuais feministas que produzem e potencializam conhecimentos e organizações de resistência em África - é a da nigeriana Oyeronke Oyewumi em "Conceituando o gênero: os fundamentos eurocêntricos dos conceitos feministas e o desafio das epistemologias africanas". Em um texto curto, mas importante para pensar a construção de gênero em sociedades iorubás, Oyeronke problematiza a categoria "mulher/mulheres" que, pela perspectiva do feminismo euro-estadunidense, não considera a pluralidade de mulheres nas sociedades africanas. Outra contribuição do texto é a de que a uma família nuclear, constituição típica das sociedades Ocidentais, reforça a desigualdade de gênero.

As afro-dominicanas Yuderkys Espinosa e Ochy Curiel trazem em seus textos algumas perspectivas relacionadas à experiência. "Fazendo uma genealogia da experiência: o método rumo a uma crítica da colonialidade da razão feminista a partir da experiência histórica na América Latina", de autoria de Yuderkys Espinosa, apresenta o conceito de colonialidade da razão feminista, que seria um conjunto de práticas que apontam a universalidade da categoria "mulher/mulheres". Tais atitudes fazem com que agendas, verdades e disputas do feminismo eurocêntrico sejam, também, de mulheres latino-americanas, o que seria uma ideia imperialista, colonialista, logo, racista. Dessa forma, a feminista promove a descolonização do feminismo, a fim de que as mulheres latino-americanas observem e considerem suas experiências e que sejam agentes ativas nas propostas de seu próprio feminismo. Retomando pensamentos e ampliando discussões de outras feministas, como Lugones e Espinosa, Ochy Curiel, em "Construindo metodologias feministas a partir do feminismo decolonial", apresenta e discute lacunas existentes no conceito de interseccionalidade. Ao fazer referências à Patricia Hill Collins, Ochy Curiel concorda com a afro-estadunidense quando esta propõe a experiência e a consciência como formas válidas para a produção de epistemologias.

O texto "Condescendência: estratégia pater-colonial de poder", de Susana de Castro, dialoga com o texto de Curiel, pois ambas pensam em quem, onde e para quem são produzidas as epistemologias. A brasileira reforça em seu texto a ideia de que a história 
contada pela perspectiva europeia foi feita através do apagamento de povos, etnias e sociedades. Além disso, há uma interessante discussão sobre a ideologia das diferenças, pois, de acordo com a autora, isso se constitui como marca de inferiorização de corpos e culturas que não são vistos como modelos de referências. As críticas finais do texto instigam os leitores a refletirem sobre o papel do Brasil na construção de epistemologias e metodologias para o seu povo e para a América Latina.

Os últimos textos da primeira parte são igualmente interessantes, pois trazem contribuições da corporeidade e da religião na produção de saber. Intitulado "A pesquisadora encarnada: uma trajetória decolonial na construção do saber científico blasfêmico", o texto de Suely Aldir Messeder apresenta a visão da antropóloga, que, ao unir o conhecimento blasfêmico ao decolonial, visa valorizar as sujeitas e os sujeitos sociais não apenas como objetos de pesquisa, mas como produtores de conhecimentos tão relevantes quanto os produzidos na academia. A partir de seu ponto de vista de pesquisadora corporeificada, a autora observar como características de identificação dos corpos constituem, constroem e performam saberes em busca de uma saída à visão eurocêntrica da produção do saber.

O texto de Marnia Lazreg, "Decolonizando o feminismo (mulheres argelinas em questão)", traz ao debate como as feministas acadêmicas rotulam as mulheres do Oriente Médio a partir da religião Islã, apagando as demais características dessas sujeitas. $\mathrm{O}$ artigo, que merece ser amplamente divulgado, tece críticas bem fundamentadas a termos que, na visão da autora, ainda carregam marcas de racismo, como "mulheres de cor", pois ainda apresenta as mulheres sem cor (as brancas) como ponto de referência para a classificação de outras mulheres. Voltando-se à relação entre gênero e religião, a autora aponta a necessidade de olhar o Islã a partir de um processo histórico que influencia na produção e reprodução da desigualdade de gênero, sem a necessidade de rotular as mulheres islâmicas por meio de um viés redutor.

Novos conceitos e novas práticas feministas são as marcas dos oito textos seguintes. Denominada "Práticas Decoloniais", a segunda parte da obra traz ações de enfrentamento à desigualdade de gênero e, além disso, apresenta o surgimento e as pedagogias de enfrentamento de feminismos que atuam por um viés decolonial, como o ecofeminismo. Já no primeiro artigo dessa segunda parte somos apresentados à proposta do feminismo comunitário, iniciado em comunidades bolivianas. Julieta Paredes Carvajal em "Uma ruptura epistemológica com o feminismo ocidental" procura mobilizar, por meio de novas práticas que atendam às necessidades das mulheres e de todos inseridos em uma comunidade, um feminismo baseado nas vivências e realidades nas práticas comunitárias, diferente das propostas do feminismo ocidental. Para a autora, uma comunidade igualitária e sem opressões hierárquicas começa na percepção da pluralidade das mulheres, pois, a partir desse processo de alteridade, nota-se a diversidade entre os demais participantes. Pode-se dizer que o feminismo comunitário criado por Carvajal se propõe como uma política que visa a equidade entre os sujeitos e as sujeitas de toda a sociedade.

A análise de uma situação cotidiana em um programa de televisão é o ponto de partida do texto "Nossos feminismos revisitados", escrito por Luiza Bairros. A 
intelectual vai apontar as relações racistas em feminismos que não consideram, por exemplo, as categorias de raça e orientação sexual. De forma contundente, a brasileira faz críticas ao feminismo hegemônico e às ideias de que a experiência da maternidade e de sexualidade definem as mulheres. Como forma de modificar essa construção, Bairros aponta o feminismo socialista e a teoria do feminist standpoint, mostrando como eles tornam heterogêneos os feminismos que incluem as categorias de gênero, raça, classe e orientação sexual, por exemplo.

Em "Pensar a partir do feminismo", Alba Barragán, Miriam Lang, Dunia Chávez e Alejandra Santillana associam o desenvolvimento econômico ao patriarcado e à opressão de mulheres. De modo claro e, de certa forma didático, as autoras apresentam os benefícios do feminismo para o desenvolvimento e como isso vem sendo articulado desde os anos 1970. Além disso, as autoras apontam os benefícios para a construção e prática do Bem Viver trazidos pelos feminismos pós-coloniais, o feminismo popular e comunitário, o feminismo andino o ecofeminismo, bem como dos governos progressistas na América Latina.

Escrito em formato de carta, como respaldo para ter maior liberdade para explorar determinados assuntos, Angela Figueiredo faz comparações entre o processo de construção e constituição de termos referentes à raça no Brasil e nos Estados Unidos, além de discutir como a influência do Estado pode mascarar ou aumentar tensões e desigualdades. "Carta de uma ex-mulata a Judith Butler" estabelece um interessante diálogo entre as teorias queer e de afirmação identitária, teorizando acerca de experiências de homofobia e de preconceito racial em contextos familiares e refletindo sobre possibilidades de enfrentamento, tanto em âmbito familiar como no social. Vale ressaltar a reflexão feita pela autora de como a representação social dos corpos de mulheres negras é perpassada por questões de gênero e de raça.

Umas das discussões mais interessantes acerca das práticas feministas é realizada por María Elvira Díaz-Benítez, em "Muros e pontos no horizonte da prática feminista: uma reflexão", no qual propõe uma descolonização do feminismo, mais precisamente da epistemologia, a partir do feminismo interseccional. A autora apresenta como as eleições de 2018 e os projetos desenvolvidos pelos políticos de direita se configuram com retrocesso, bem como uma perseguição ao feminismo e demais movimentos sociais. A partir disso, ela tece suas reflexões de como o feminismo pode se constituir enquanto ponte por meio da interseccionalidade, que questiona o lugar central ocupado pela categoria de gênero nas ações feministas, e como as abolicionistas tentam moralizar os feminismos - a exemplo do embate com o movimento das prostitutas - e não incluem outros corpos - como os de mulheres trans - em sua agenda de luta.

O ecofeminismo é o tema central do texto de Maria da Graça Costa: "Agroecologia, ecofeminismos e bem viver: emergências decoloniais no movimento ambientalista brasileiro". Ao fazer referência à participação das feministas camponesas, indígenas e negras na construção de um espaço decolonial de resistência no ecofeminismo e na agroecologia, Costa reflete acerca da relação dessas mulheres com o feminismo, pois muitas daquelas que fazem parte dos movimentos campesinos 
e do MTST, por exemplo, não se declaram feministas, ainda que batalhem contra a opressão de gênero e lutem para que as mulheres tenham melhores condições de vida. Em "Por uma concepção amefricana de direitos humanos", Thula Pires aborda a questão dos direitos humanos por um viés afrocentrado, baseado nos conceitos de amefricanidade e do pretoguês de Lélia Gonzalez. A autora vai mostrar como os ideais dos Direitos Humanos atendem a apenas uma parcela da população mundial, criando hierarquias entre os seres humanos, tornando-o insuficiente. Além disso, Pires discute a importância da decolonialidade para que se amplie as ações propostas pelos Direitos Humanos, observando as sujeitas e os sujeitos que passam por formas de opressão e não são assistidos pelas normas universais.

Por fim, Cláudia de Lima Costa faz uma análise do quadro Olympia (1867), de Édouard Manet, para iniciar a discussão sobre a decolonialidade e os desafios do feminismo latino-americano. Em "Feminismos decoloniais e a política e a ética da tradução", Costa inicia uma interessante reflexão entre feminismo e tradução cultural, apresentando rupturas epistêmicas, e usando como exemplos as comunidades indígenas andinas e a noção de equivocação. $\mathrm{O}$ equívoco seria uma perspectiva possível para subverter as teorias e as construções epistemológicas eurocentradas de gênero e raça. A autora conclui trazendo a leitura de uma "Olympia traduzida” (1988), proposta por Yasumasa Morimura, permitindo reflexões outras que estimulam o rompimento com elementos da colonialidade.

Na terceira e última parte denominada "Outras línguas: três artistas brasileiras", as obras das artistas plásticas Adriana Varejão, Rosana Paulino e Marcela Cantuária permitem discussões acerca do pensamento latino-americano. Além disso, é possível perceber nas obras um convite para pensar em novas formas de existir e representar artisticamente os povos que compõem a América Latina. As obras - que vão de pinturas a instalações - contribuem para que os leitores percebam relações entre o fazer artístico e o olhar decolonial.

Os textos escolhidos por Heloisa Buarque de Hollanda apresentam reflexões que rompem com as matrizes coloniais de poder, bem como trazem exemplos de ações e de políticas públicas possíveis e sustentáveis, que respeitam as histórias dos povos originários, a diversidade e os diferentes modos de como as mulheres resistem e encontram saídas contra a opressão em suas comunidades a partir de um olhar decolonial. O livro organizado por Heloísa Buarque de Hollanda possibilita entender não só o feminismo decolonial, mas outros feminismos que buscam criar epistemologias que atuem na promoção da equidade entre as sujeitas e os sujeitos dos países do Sul. Pensamentos feministas hoje: perspectivas decoloniais é leitura obrigatória para quem quer entender o processo de emancipação das mulheres na América Latina, em África e no Oriente Médio, e as lutas para a construção de sociedades menos desiguais.

Recebido em 15/11/2020.

Aceito: 05/12/2020. 